\title{
Seismic rumbling foretold Congo eruption
}

Tom Clarke, London

Two seismological stations on Mount Nyiragongo in eastern Congo gave several days' advance warning of the volcano's possible eruption, scientists working in the area say.

But the lack of a functioning government in the war-torn region may have prevented the evacuation of the nearby city of Goma, where 45 were confirmed dead and an existing humanitarian crisis was worsened by the eruption.

For the past decade, a Japanese team has sought to maintain a seismic network at the volcano. In 1994, five monitoring units were donated by the US Geological Survey's Volcano Disaster Assistance Program (VDAP) to form the Goma Volcano Observatory.

But fighting in the area and looting of equipment by armed militia camped on the volcano itself regularly forced volcanologists to flee, according to Jacques Durieux, director of the Active Volcanoes Study Group in Lyon, France, who last visited Mount Nyiragongo with VDAP scientists in 1994.

According to the VDAP, only two monitoring stations were working properly before the eruption. VDAP scientists nevertheless received a warning on 12 January - five days before the first eruption - of the possibility of "abnormal seismic activity".

Durieux, who spoke with Congolese volcanologists on the day of the eruption, says that efforts were made to raise the alarm, but the lack of governance in Goma makes it unlikely that any plan to evacuate the city could have been implemented. Local volcanologists "have no staff and no pay", says Hawaii-based volcano consultant Jack Lockwood, who has accompanied Durieux on previous trips to Mount Nyiragongo.

Durieuxnow wants to improve the observation of Mount Nyiragongo and its neighbour, Mount Nyamuragira, some $14 \mathrm{~km}$ away, which is also active. But he says that "we can't expect developing countries to pay".

Mount Nyiragongo last erupted in 1977, killing around 500 people, and threatened to do so again in June 1994, when some 800,000 refugees from Rwanda's civil war were camped on its slopes. Last week's eruption

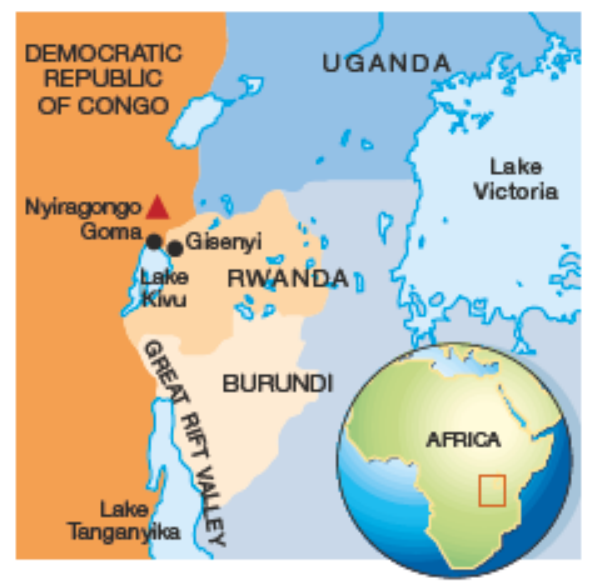

was the largest in the volcano's history, according to geological evidence.

Predicting future eruptions of an active volcano such as Nyiragongo will require a far more elaborate monitoring system than the two stations currently in place, say VDAP scientists. The VDAP and other agencies have provided more comprehensive monitoring of volcanoes elsewhere in the developing world, but such monitoring is only carried out at the request of the host government. With the province of North Kivu, where Goma is situated, controlled by Rwandan-backed rebels, such a request was not forthcoming from the government of the Democratic Republic of Congo in Kinshasa, say VDAP officials.

\section{UN attempts to boost biosafety in developing world}

\section{David Adam, London}

A scheme launched last week will help up to 100 of the world's poorest nations to obtain basic technical knowledge about genetically modified crops.

The US\$38-million scheme, unveiled in Nairobi on 16 January by the United Nations Environment Programme (UNEP), is designed to help the countries protect their interests more effectively in negotiations with agricultural suppliers, the food industry and drug companies.

Advocates of the scheme say it will help to conserve biodiversity and foster economic development. But critics argue that the money will not go very far and that the increased knowledge may confuse countries about the risks of transgenic technology.

The three-year programme will centre on "building capacity for assessing risks, establishing adequate information systems and developing expert human resources in the field of biosafety", says Christopher Briggs, manager of the project.

But with funds of only around
US $\$ 400,000$ per country - provided by the Global Environment Facility, a joint venture of the United Nations and the World Bank Briggs concedes that this is just a "first step". Follow-up funds of up to $\$ 1.4$ million will be available to countries that create the necessary administration, he says.

The initiative follows a trial scheme with several developing countries. In one of them, Namibia, officials report that the money will eventually enable local scientists to test for transgenic crops independently.

But the project's small scale makes it "like offering swimming lessons to people in the Sahara", says Calestous Juma, director of the Science, Technology and Innovation Program at Harvard University, which focuses on the role of research in developing countries. He fears that resources may be diverted "from areas where the risks are known to areas where they are still being debated".

Participation in the scheme should allow countries to adhere to the Cartagena Protocol on Biosafety, an international agreement on approaches to agricultural

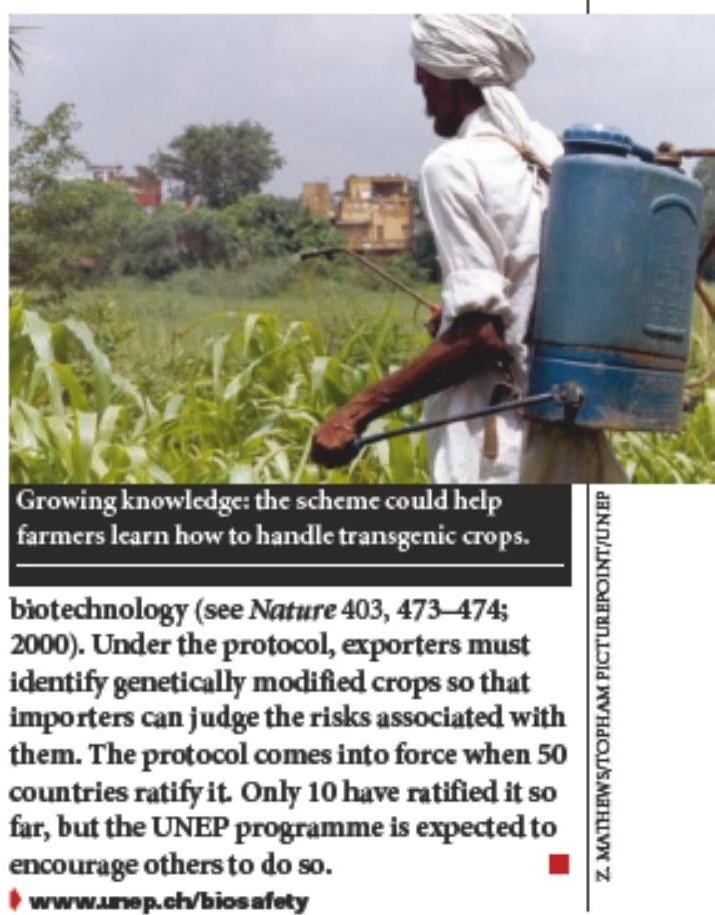

wrwwsmep.ch/biosafety
Mount Nyiragongo in castern Congo killed dozens in its biggest-ever eruption. 